\title{
Long travel distance for health care and poor adherence to breast cancer screening programs as predictors of patient delay
}

Milena Edite Case de Oliveira ${ }^{1}$; Tácila Thamires de Melo Santos ${ }^{1}$; Lorena Sofia dos Santos Andrade ${ }^{1}$; Kedma Anne Lima Gomes ${ }^{\text {; }}$ Tiago Almeida de Oliveira ${ }^{2}$; Mathias Weller ${ }^{*}$

${ }^{1}$ Programa de Pós-graduação em Saúde Publica. Universidade Estadual da Paraíba (UEPB). Campina Grande-Paraíba, Brazil ${ }^{2}$ Departamento de Estatística. Universidade Estadual da Paraíba (UEPB). Campina Grande-Paraíba, Brazil

\author{
*Corresponding Author (s): Mathias Weller \\ Programa de Pós- Graduação em Saúde Publica. Univer- \\ sidade Estadual da Paraíba (UEPB). Central Integrada de \\ aulas. Rua Domitila Cabral de Castro, s/n 30andar - sala \\ 310, Bairro Universitário. CEP. 58.429-570. Campina \\ Grande. Paraíba. Brazil \\ Tel: 0055- 83-9941-8090; \\ Email: mathiasweller@uepb.edu.br
}

Received: Apr 11, 2019

Accepted: Jun 10, 2019

Published Online: Jun 12, 2019

Journal: Annals of Epidemiology and Public health

Publisher: MedDocs Publishers LLC

Online edition: http://meddocsonline.org/

Copyright: (C) Weller M (2019). This Article is distributed under the terms of Creative Commons Attribution 4.0 International License

Keywords: Breast cancer; Treatment delay; Patient delay; Health service

\begin{abstract}
Patient delay (PD) is a leading cause of advanced stage of disease and poor prognosis among Brazilian breast cancer patients. The present study addressed socio-demographic variables and their impact on PD. Odds Ratios (OR) and Confidence Intervals $(\mathrm{Cl})$ were determined using regression analysis. Data of 103 breast cancer patients were obtained from medical records and interviews. All patients detected first symptoms of breast cancer on their own. On average, patients were seeking for medical help 67.5 ( $s=124.1)$ days after recognition of symptoms. More than 60 days between recognition of symptoms and first medical visit was defined as PD in 33 (32.0\%) cases. Low and intermediate educational level increased chance of PD, 1.22 (95\% Cl: 0.33-4.48) and 1.92 (95\% Cl: 0.53-7.00) fold. Having no stable relationship increased chance of PD 2.04 (95\% Cl: 0.88-4.73) fold. Patients without a private health insurance had a $1.90(95 \% \mathrm{Cl}$ : 0.49-7.32) increased chance of PD. Women, who had not at all, or rarely performed medical visits at their own living place, had a 6.25 (0.76-51.33) increased chance of PD $(p<0.05)$. Patients who had never performed mammography and CBE had a 1.78 (0.57-5.53) and 1.47 (0.44-4.89) increased chance of PD. Not having a health service at the own living place was the most prominent causal factor of PD. As tumours of patients were not discovered during medical exams, the negative association between adherence to prevention programs and $P D$, points to additional attitudes of participating women that reduced treatment delay.
\end{abstract}


Introduction

Changing lifestyle and longer life expectation have led to an increase in breast cancer incidence in developing countries, whereas incidence remained stable or even declined in most developed countries [1]. Latin American countries are characterized by high mortality-to-incidence ratios and the total number of deaths due to breast cancer was expected to double between 2008 and 2030 to 73,542 cases [2,3]. Furthermore, it was estimated that $30 \%$ to $40 \%$ of breast cancer patients in these countries are at advanced stages of the disease (III and IV) [3].

In Brazil, the largest Latin American country, 59,700 new cases were predicted for the year 2018 and breast cancer is currently contributing to $29.5 \%$ of all cancer cases among women [4]. In southern regions of Brazil, including the country's largest urban centres, São Paulo and Rio de Janeiro, the incidence of breast cancer has remained stable. This is in contrast to the Northeastern region, where increased life expectancy and changing lifestyle have led to an increase of the disease between 2005 and 2018, from 27.23 to 63.98 new cases per 100,000 women [4,5]. Additionally, from 1990 to 2011, breast cancer mortality rates declined in São Paulo and Rio de Janeiro, but increased significantly in states of the North- eastern region within the same 20-year time interval [6].

Treatment delays are considered to be one of the main reasons for the high mortality-to-incidence ratios in developing countries [7]. Previous studies have associated treatment delays with advanced stage of the disease and poor prognosis of breast cancer patients $[8,9]$. Literature generally refers on time intervals between recognition of symptoms and breast cancer treatment as treatment delay. Furthermore, treatment delay is subdivided into two main time intervals [7, 10,11]: System Delay (SD) refers to the time interval between first medical visit and treatment initiation. Patient Delay (PD) in contrast, refers to the time interval between recognition of breast cancer symptoms and first medical visit.

Low income, low educational level, no family history of breast cancer and no help from family members, are among the most cited variables associated with PD [12-16]. Additionally, fear and poor knowledge about disease symptoms contribute to PD $[13,14,17,18]$. There are only few Brazilian studies about PD [19-24]. These studies did not clearly distinguish between $P D$, respectively SD and only two of them were performed in the North- eastern region of Brazil $[20,23]$. Studies also have not analysed the travel distance to the health service after recognition of symptoms, or the possible PD differences among women who sought first medical help in public or private health service centres after detection of symptoms. The Brazilian "Sistema Único de Saúde" (SUS) is a public health care system that provides free access to health facilities for all Brazilians. Additionally, about $25 \%$ of the Brazilian population has access to private health services, financed by individual health insurance $[25,26]$. This means that women who recognize symptoms have the option to seek first medical help in the public health service network or in a private health service.

Increasing incidence and mortality rates in the North- eastern region of Brazil underline the need to understand the reasons for PD. The present descriptive study aimed at identifying access barriers and socio- economic variables as causal factors for PD. The present study compared PD among women who sought first medical help in the public and private health service system. The impact of travel distance to health service centres on PD was also assessed. Furthermore, the study aimed at identifying underlying socio- economic variables that affect PD.

\section{Material and method}

\section{Study population}

The study protocol was reviewed and approved by the Brazilian National Research Ethics Committee (CONEP; Nr.: CEP-UEPB: 63083816000005187). Written informed consent was obtained from each participant to participate in this study and to publish data.

Patient data were obtained from two Brazilian cancer treatment referral centres: the Napoleão Laureano Hospital in João Pessoa and the Fundação Assistencial da Paraíba Hospital in Campina Grande. We refer to each as HNL and FAP, respectively. João Pessoa, the capital of the state of Paraíba, has about 800,000 inhabitants and is located on the state coast [27]. Campina Grande, with about 400,000 inhabitants, is the second largest urban centre in Paraíba and is located about $120 \mathrm{~km}$ away from the state capital in the inner state [27]. Paraíba has mixed-ethnic population of indigenous, African and European ancestry.

\section{Data sampling}

Data were collected between October 2016 and September 2018. Only patients who received treatment within this period in one of the both referral centres, FAP or HNL, were included in the study. Patients with disease recurrence and those with cognitive problems were excluded. Furthermore, the study did not include patients whose tumour was detected by clinical breast exam (CBE), mammography screening or any other image producing technique. Only patients who recognized first symptoms of invasive breast tumour within the last three years were included in the study. No differences were observed among data obtained from patients treated at FAP or HNL. Clinical and histopathological data were obtained from medical records. Data about first medical consultation were also obtained from medical records.

A structured questionnaire was administered to patients under chemotherapy and radiotherapy treatment at both hospitals. Interviews were performed by one of the researchers. Patients were asked about prevention behaviour, socio-economic status including marital status, income, occupation status, and health insurance status, educational level, place and type of medical visits and year, respectively the month of recognition of first symptoms. Of 155 women with invasive breast cancer, 52 did not remember the date of first symptom recognition or were not sure about it, being then excluded from the study. Among the remaining 103 patients, time interval of 60 days between first symptom recognition and first medical visit was defined as PD.

Educational level was defined as follows: 1. Low: Illiterate or incomplete and complete elementary education of nine years of basic school education, respectively incomplete high school; 2. Intermediate: Complete high school of 12 years; 3 . High: Any type of high school or college meant that the patient had more than 12 years of schooling or university education. Minimum wage and multiple values were used to characterize income. This is a popular and well-known method used to define economic level among low- and middle-class subjects. Minimum wage or less was defined as "low" income, whereas minimum 
wage multiples were defined as "high" income. The minimum wage in 2018 was $R \$ 954,00$ (US\$281.60 on 20 April 2018) per month. Information regarding ethnic origin was obtained by self-report of participating women.

The Brazilian Ministry of Health recommends annual CBE for women aged 40 years or older. The Ministry of Health recommends biannual mammography for women aged 50-69 years, whereas the Brazilian Society of Mastology recommends annual mammography screening (MS) starting at 40 years of age $[28,29]$. For healthy women aged 70 or older, regular MS is recommended $[28,29]$. Biannual and annual mammography screening, respectively, annual performance of $C B E$, both were defined as regular (Table 1).

\section{Statistical analysis}

Data were tabulated in Excel ${ }^{\circledR}$ software (version 10; MICROSOFT, 2010) and all statistical analyses were performed with SPSS STATISTICS ${ }^{\text {TM }}$ software (SPPS; IBM company; version 24). Nominal logistic regression results for unadjusted variables were presented as odd ratios (OR) and $95 \%$ confidence interval $(95 \% \mathrm{Cl})$. Likelihood ratio test was applied to analyse significance level of each variable.

\section{Results}

A time interval of more than 60 days between recognition of symptoms and first medical visit was defined as PD in 33 (32.0\%) cases. On average, the 103 patients sought for medical help $67.5(s=124.1)$ after recognition of symptoms. Of all patients, 56 (54.4\%) sought medical help within the first 30 days after recognition of symptoms. Time interval varied from 0 for those who immediately sought help to maximum of 943 days.

The mean age of study patients was 53.08 years ( $s=11.54)$. Of 103 patients, $40(32.9 \%)$ and $63(67.1 \%)$ aged < 50 years, respectively $\geq 50$ years (Table 1). Of 102 patients, 45 (44.1\%) and 55 (53.9\%) were characterized as low educational level and low income (Table 1). Furthermore, 67 (66.3\%) out of 101 and $88(86.3 \%)$ out of 102 patients were unemployed, respectively, and had no private health insurance (Table 1). Of 103 patients, $62(60.2 \%)$ had stable relationship. Regarding medical visits, 78 (76.5\%) out of 102 patients informed never or rarely sought medical help at their own living place (Table 1). Of 102 patients, $46(45.1 \%)$ never or rarely visited a basic health service unit (Table 1). Regarding adherence to screening programs, 36 (51.4\%) and $35(50.0 \%)$ out of 70 patients claimed to have performed regular mammography and clinical breast examination (Table 1).

Patients with low and intermediate educational level had 1.22 (95\% Cl: 0.33-4.48) and $1.92(95 \% \mathrm{Cl}: 0.53-7.00)$ increased chance of PD, compared to women with high educational level (Table 1). Having no stable relationship increased the chance of PD by 2.04 (95\% Cl: 0.88-4.73) times, compared to women who live in a stable relationship (Table 1). Patients without private health insurance had $1.90(95 \% \mathrm{Cl}: 0.49-7.32)$ increased chance of PD, compared to women with private health insurance (Table 1). Women who did not have medical visits at their living place had 6.25 (0.76-51.33) increased chance of PD compared to women who performed medical visits at their living place (Table 1). Women who rarely, never and sometimes visited a basic health service unit had 2.66 (95\% $\mathrm{Cl}: 0.96-7.36)$ and 2.76 (0.967.36) increased chance of PD, compared to those with regular visits (Table 1). Of the 36 women who regularly visited a basic health service unit, two (5.6\%) claimed to perform medical vis- its always at their own living place. Furthermore, patients who had never performed mammography and CBE had 1.78 (0.575.53) and 1.47 (0.44-4.89) increased chance of PD, compared to those who performed mammography regularly (Table 1 ).

Of 96 patients, 61 (63.5\%) perceived nodules as first symptom of the disease (Table 2). Of 85 patients, $53(62.4 \%)$ presented at advanced stage (III or IV) of the disease (Table 2). Of 88 patients, $55(62.5 \%)$, respectively, $30(34.1 \%)$, had tumours of histological grades 2 and 3 (Table 2). Statistical analysis did not indicate significant associations between PD and tumour stage or grade.

\section{Discussion}

More than $50 \%$ of patients in the present study sought medical help within the first 30 days after recognition of symptoms. This value is very similar to that of a previous study performed in the state of São Paulo, were $52.4 \%$ of women sought medical help within 30 days [19].

Present results indicated that low and intermediate educational level was associated with PD. This is in agreement with previous studies from Nigeria, Rwanda, Tunisia, Turkey, Libya, Pakistan, Colombia, Haiti, Brazil, and the USA, which also identified low educational level and poor literacy status as causal factors for PD [13-16,19,24,30-35]. Unlike educational level, low or high income was not associated with PD among patients of the present study and negative employment status increased the chance of PD only slightly. This is in contrast with previous studies from Colombia, Mexico, Senegal, Hong Kong and the USA, which identified low $[12,34,36,37]$ or high [38] income as decisive factor for PD.

Patients of the present study who did not live in a stable relationship were twice more likely of having increased chance of PD, compared to those who lived in a stable relationship. Studies performed in Pakistan, Malaysia, Mexico, the United Kingdom and the USA revealed comparable findings [13,36,38-41]. Living in a stable relationship may increase self- care and breast cancer prevention behaviour of women [36].

Present results indicated that patients without private health insurance were at increased risk of PD. In agreement with this finding, previous studies performed in Colombia, Haiti, Tunisia, India and the USA, also revealed that high financial costs of treatment and not having a private health insurance were serious treatment barriers, finally leading to PD $[16,33,34,42-45]$.

Patients of the present study were asked if they had performed medical visits for any type of disease before diagnosis of breast cancer, generally at their own living place, or somewhere else. Data analysis revealed that patients who had performed it rarely or never at their own living place were six times more likely of having increased chance of PD, if compared to those who had performed medical visits always at their own living place. Furthermore, of 36 patients who had regularly visited basic health service units, only two performed it at their own living place. This result points to the existence of access barrier for women to seek for medical help. Present data indicate that the lack of medical services at living place increased PD. Long distances to health care centres as important causal factor for PD was identified in studies conducted at low- and middle-income countries like Tunisia, Nigeria, Brazil, India and Thailand, but also the USA $[20,33,35,44,46,47]$. Price and colleagues (2012) emphasized that long distance to health care centre is one of the most serious problems of treatment delay in developing 
countries [48].

Authors from Australia, Estonia, Colombia, Brazil, United Kingdom and the USA emphasized that performance of breast cancer screening reduced time intervals between tumour detection and treatment initiation [24,49-54]. In the present study, breast cancer was not detected during medical exams. Instead, women detected symptoms first by themselves and searched for medical help after recognition of symptoms. Furthermore, present data argued in favour of the scenario that regular visit to basic health service units, performance of mammography and CBE were all associated with decreased chance of PD. The following should be highlighted: Tumours were not discovered by mammography and CBE, but women who performed them on a regular basis sought faster medical help as they had discovered symptoms. This indicated that women's prevention behaviour was associated with other attitudes that favoured faster medical help seeking behaviour. A previous Brazilian study identified fear of breast cancer and poor knowledge of symptoms as variables that increased PD (Oshiro et al., 2014). This could indicate that women who adhere to screening programs also have better knowledge of symptoms, less fear of breast cancer and for these reasons are more likely to seek early medical help.

A limitation of the present study was that symptom recognition, attitudes and psychological factors like fear of disease, selfcare and self-esteem were not analysed in detail. The impact of family history on women's behaviour was not analysed. Patients were asked about events in the past, before disease diagnosis. The developed questionnaire may have caused a bias in recalling exact information. This could have resulted in misclassification of information and/or lack of comparability of results to those of prior studies that have used standard instruments. Low number of patients led to low data resolution. For this reason, regression modelling was not performed and it remains unclear which independent variables essentially contribute to PD.

The results have indicated that low educational level, not living in a stable relationship and not having a private health insurance were variables that increased PD in the population from North-eastern Brazil. Furthermore, long distance to health care service was identified as the most important variable of $P D$. The findings of the present study are in agreement with international literature. Surprisingly, despite the fact that patient tumours were not detected during medical exams, women who had participated on a regular basis on screening programs had reduced $\mathrm{PD}$, compared to women who have not. This points to additional important attitudes associated with women's screening behaviour that reduce PD. Future studies about PD in Northeastern Brazil should elucidate these underlying attitudes and psychological aspects in more detail.

\section{Tables}

Table 1: Chance of delay, defined as first medical visit of $>60$ days after recognition of symptoms, expressed as odds ratio (OR) and confidence intervals $(95 \% \mathrm{Cl})$, for each variable.

\begin{tabular}{|c|c|c|}
\hline Variable & N (\%) & OR $(95 \% \mathrm{Cl})$ \\
\hline \multicolumn{3}{|l|}{ Age $(N=103)$} \\
\hline$\geq 60$ years & $30(32.3 \%)$ & Ref. \\
\hline 50 - 59 years & $33(34.8 \%)$ & $0.87(0.30-4.83)$ \\
\hline 40 - 49 years & $27(22.6 \%)$ & $0.84(0.27-2.59)$ \\
\hline$<40$ years & $13(10.3 \%)$ & $1.25(0.32-4.83)$ \\
\hline
\end{tabular}

\section{Education level $(\mathrm{N}=102)$}

\begin{tabular}{|l|c|c|}
\hline High & $16(15.7 \%)$ & Ref. \\
\hline Intermediate & $41(40.2 \%)$ & $1.92(0.53-7.00)$ \\
\hline Low & $45(44.1 \%)$ & $1.22(0.33-4.48)$ \\
\hline Income (N= 102) & $21(20.6 \%)$ & Ref. \\
\hline High & $26(25.5 \%)$ & $1.47(0.44-4.85)$ \\
\hline Middle & $55(53.9 \%)$ & $0.75(0.25-2.22)$ \\
\hline Low & & \\
\hline Occupation status (N= 101) & $34(33.7 \%)$ & Ref. \\
\hline Employed & $67(66.3 \%)$ & $1.26(0.51-3.07)$ \\
\hline Unemployed & &
\end{tabular}

Stable relationship $(\mathrm{N}=103)$

\begin{tabular}{|c|c|c|}
\hline Yes & $62(60.2 \%)$ & Ref. \\
\hline No & $41(39.8 \%)$ & $2.04(0.88-4.73)$ \\
\hline \multicolumn{3}{|c|}{ Private Health Insurance ( $N=102)$} \\
\hline Yes & $14(13.7 \%)$ & Ref. \\
\hline No & $88(86.3 \%)$ & $1.90(0.49-7.32)$ \\
\hline \multicolumn{3}{|c|}{ Religion ( $N=102$ ) } \\
\hline Protestant & $30(29.4 \%)$ & Ref. \\
\hline Catholic & $72(70.6 \%)$ & $1.46(0.57-3.76)$ \\
\hline \multicolumn{3}{|c|}{ Medical visits at living place* $(N=102)$} \\
\hline Always & $11(10.8 \%)$ & Ref. \\
\hline Sometimes & $13(12.7 \%)$ & $1.82(0.14-23.25)$ \\
\hline Rarely/never & $78(76.5 \%)$ & $6.25(0.76-51.33)$ \\
\hline
\end{tabular}

Visit to basic health service unit $(\mathrm{N}=102)$

\begin{tabular}{|c|c|c|}
\hline Regular $^{2}$ & $36(35.3 \%)$ & Ref. \\
\hline Sometimes & $20(19.6 \%)$ & $2.76(0.96-7.36)$ \\
\hline Rarely/Never & $46(45.1 \%)$ & $2.66(0.96-7.36)$ \\
\hline \multicolumn{3}{|c|}{ Performance of mammography $(\mathrm{N}=70)$} \\
\hline Regular $^{1}$ & $36(51.4 \%)$ & Ref. \\
\hline Sometimes & $4(5.7 \%)$ & $4.14(0.49-34.75)$ \\
\hline Never & $30(42.9 \%)$ & $1.78(0.57-5.53)$ \\
\hline \multicolumn{3}{|c|}{ Performance of CBE ( $N=70)$} \\
\hline Regular $^{2}$ & $35(50.0 \%)$ & Ref. \\
\hline Sometimes & $9(12.9 \%)$ & $2.00(0.40-10.05)$ \\
\hline Never & $26(37.1 \%)$ & $1.47(0.44-4.89)$ \\
\hline
\end{tabular}

${ }^{*} \mathrm{p}<0.05 ;{ }^{1}$ Each year or each second year; ${ }^{2}$ Each year 
Table 2: Clinical and histopathological characteristics of breast cancer patients $(\mathrm{N}=103)$.

\begin{tabular}{|c|c|}
\hline Variable & $\mathbf{N}(\%)$ \\
\hline \multicolumn{2}{|c|}{ Perceived symptoms before diagnosis } \\
\hline Nodule & $61(63.5 \%)$ \\
\hline Nodule and other symptoms & $18(18.8 \%)$ \\
\hline Other symptoms ${ }^{1}$ & $17(17.7 \%)$ \\
\hline Missing & 7 \\
\hline \multicolumn{2}{|l|}{ TNM } \\
\hline । & $4(4.7 \%)$ \\
\hline II & $28(32.9 \%)$ \\
\hline III & $38(44.7 \%)$ \\
\hline IV & $15(17.7 \%)$ \\
\hline Missing & 18 \\
\hline \multicolumn{2}{|l|}{ Histological Grade } \\
\hline 1 & $3(3.4 \%)$ \\
\hline II & $55(62.5 \%)$ \\
\hline III & $30(34.1 \%)$ \\
\hline Missing & 15 \\
\hline
\end{tabular}

${ }^{1}$ Pulmonary haemorrhage, clear fluid; breast depression; swollen breast with areolar retraction; painful breast abscess; inverted areola, inflamed breast; breast pain; breast regurgitation; "burning sensation"; phlogistic signs in left breast; mammary protuberance; breast crease.

\section{references}

1. Torre LA, Siegel RL, Ward EM, Jemal A. Global Cancer Incidence and Mortality Rates and Trends- An Update. Cancer Epidemiol Biomarkers Prev. 2016; 25: 16-27.

2. Carioli GM, Malvezzi T, Rodriguez P, Bertuccio E, Negri, La Vecchia C. Trends and predictions to 2020 in breast cancer mortality: Americas and Australasia. Breast. 2018; 37: 163-169.

3. Justo $\mathrm{N}$, Wilking $\mathrm{N}$, Jönsson $\mathrm{B}$, Luciani S Cazap E. A review of breast cancer care and outcomes in Latin America. Oncologist. 2013; 18: 248-256.

4. Instituto Nacional do Câncer. (INCA). 2018. Estimativa 2018: Incidência de câncer no Brasil.

5. Instituto Nacional do Câncer (INCA). 2005. Estimativa 2005: Incidência de câncer no Brasil.

6. Gonzaga, CMR, Freitas-Junior R, Curado MP, Sousa ALL, Souza-Neto JA, Souza MR. Temporal trends in female breast cancer mortality in Brazil and correlations with social inequalities: ecological time-series study. BMC Public Health. 2015; 15:96.

7. Unger-Saldaña K. Challenges to the early diagnosis and treatment of breast cancer in developing countries. World J Clin Oncol. 2014; 5: 465-477.

8. Caplan L. Delay in Breast Cancer: Implications for Stage at Diagnosis and Survival. Front Pub Health. 2014; 2: 1-5.
9. Williams F. Assessment of Breast Cancer Treatment Delay Impact on Prognosis and Survival: a Look at the Evidence from Systematic Analysis of the Literature. A Pilot Study. J Canc Biol Res. 2015; 3: 1071.

10. Ramirez AJ, Westcombe AMAM, Burgess CC, Sutton S, Littlejohns P Richards MA. Factors predicting delayed presentation of symptomatic breast cancer: a systematic review. Lancet. 1999; 353: 1127-1131.

11. Richards MA, Westcombe AM, Love SB, Littlejohns P, Ramirez AJ. Influence of delay on survival in patients with breast cancer: a systematic review. Lancet. 1999; 353: 1119-1126.

12. Gueye M, Gueye SMK, Diallo M, Thiam O, Mbodji A, et al. Sociodemographic Factors Associated with Delays in Breast Cancer. Open J Obstet Gynecol. 2017; 7: 455-463.

13. Memon ZA, Shaikh AN, Rizwan S, Sardar MB. Reasons for Patient's Delay in Diagnosis of Breast Carcinoma in Pakistan. Asian Pac J Cancer Prev. 2013; 14: 7409-7414.

14. Ozmen V, Boylu S, Ok E, Canturk NZ, Celik V, et al. Factors affecting breast cancer treatment delay in Turkey: a study from Turkish Federation of Breast Diseases Societies. Eur J Public Health. 2014; 25: 9-14.

15. Pace LE, Empunga T, Hategekimana V, Dusengimana JMV, Habineza $\mathrm{H}$, et al. Delays in Breast Cancer Presentation and Diagnosis at Two Rural Cancer Referral Centers in Rwanda. Oncologist. 2015; 20: 780-788.

16. Sharma K, Costas A, Damuse R, Hamiltong- Pierre J, Pyda $J$, et al. The Haiti Breast Cancer Initiative: Initial Findings and Analysis of Barriers-to-Care Delaying Patient Presentation. J Oncology. 2013; 206-367.

17. Moodley M, Cairncross L, Naiker T, Constant D. From symptom discovery to treatment - women's pathways to breast cancer care: across-sectional study. BMC Cancer. 2018; 18:312.

18. Stamatovic LJA, Vasovic SA, Trifunovic JB, Boskov NC, Gajic $Z D$, et al. Factors influencing time to seeking medical advice and onset of treatment in women who are diagnosed with breast cancer in Serbia. Psychooncology. 2018; 27: 576-582.

19. Barros FA, Uemura G, Macedo JLS. Tempo para acesso ao tratamento do câncer de mama no Distrito Federal, Brasil Central. Rev Bras Ginecol Obstet; 2013; 35: 458-463.

20. Cavalcanti LPG, Simões PSF, Silva MRR, Galdino PNR. Assistência em mastologia em uma unidade de referência do Sistema Único de Saúde no Ceará, Brasil. Rev Bras Câncer. 2012; 58: 63-69.

21. Lourenço AV. Women cancer prevention and pharmaceutical contribution. Braz J Pharmacol Sciences. 2010; 46: 45-52.

22. Oshiro ML, Bergmann A, Silva RG, Costa KC, Travaim IEB, et al. Câncer de Mama Avançado como Evento Sentinela para Avaliação do Programa de Detecção Precoce do Câncer de Mama no Centro-Oeste do Brasil. Rev Bras Câncer. 2014; 60: 15-23.

23. Paiva CJK, Cesse EAP. Aspectos Relacionados ao Atraso no Diagnóstico e Tratamento do Câncer de Mama em uma 
Unidade Hospitalar de Pernambuco. Rev Bras Câncer. 2015; 61: 23-30.

24. Rezende MCR, Koch HA, Figueiredo JA, Thuler LCS. Causas do retardo na confirmação diagnóstica de lesões mamárias em mulheres atendidas em um centro de referência do Sistema Único de Saúde no Rio de Janeiro. Rev Bras Ginecol Obstet. 2009; 31: 75-81.

25. Malta DC, Stopa SR, Pereira CA, Szwarcwald CL, Oliveira $M$, Reis AC. Private Health Care Coverage in the Brazilian population, according to the 2013 Brazilian National Health Survey. Ciência \& Saúde Col. 2017; 22: 179-190.

26. McGregor AJ, Siqueira CE, Zaslavsky AM, Blendon RJ. Do elections matter for private-sector healthcare management in Brazil? An analysis of municipal health policy. BMC Health Serv Res. 2017; 17: 483-496.

27. Brazilian Institute of Geography and Statistics (IGBE). 2010.

28. Urban LABD, Chala LF, Bauab SP, Schaefer MB, Santos RP, et al. Recomendações do Colégio Brasileiro de Radiologia e Diagnóstico por Imagem, da Sociedade Brasileira de Mastologia e da Federação Brasileira das Associações de Ginecologia e Obstetrícia para rastreamento do câncer de mama por métodos de imagem. Radiol Bras. 2012; 45: 6.

29. Instituto Nacional do Câncer. (INCA). 2016. Brazilian guidelines for the screening of cervical cancer.

30. Black AR, Woods- Giscombé C. Applying the Stress and 'Strength' Hypothesis to Black Women's Breast Cancer Screening Delays. Stress Health. 2012; 28: 389-396.

31. Ceballos-García, GY, Giraldo-Mora CV. "Autobarreras" de las mujeres al diagnóstico y tratamiento oportuno del cáncer de mama. Aquichán. 2011; 11: 140-157.

32. Ermiah, E, Abdalla F, Buhmeida A, Larbesh E, Pyrhönen $S$, Collan Y. Diagnosis delay in Libyan female breast cancer. BMC Res Notes. 2012; 21: 452.

33. Landolsi A, Gahbiche S, Chaafii R, Chabchoub I, Fatma LB et al. Reasons of diagnosis delay of breast cancer in Tunisian women (160 patients in central region of Tunisia). Tunis Medicine. 2010; 88: 894-897.

34. Piñeros M, Sánchez R, Cendales R, Perry F, Ocampo R. Patient delay among Colombian women with breast cancer. Salud Pub Mex. 2009; 51: 372-380.

35. Ukwenya AY, Yusufu LMD, Nmadu PT, E. Garbaa S, Ahmed A. Delayed treatment of symptomatic breast cancer: The experience from Kaduna, Nigeria. South African J Surg. 2008; 46: 106-110.

36. Unger- Saldaña K, Ventosa- Santaulària D, Mirnada A, Verduzco- Busto G. Barriers and explanatory mechanisms of delays in the patient and diagnosis intervals of care for breast cancer in Mexico. Oncologist. 2018; 23: 440-453.

37. Yau TK, Choi CW, Ng E, Yeung R, Soong IS, Lee AWM. Delayed presentation of symptomatic breast cancers in Hong Kong: experience in a public cancer center. Hong Kong Med J. 2010; 16: 373-377.

38. Sheppard VB, Isaacs C, Luta G, Willey SC, Boisvert M, et al. Narrowing Racial Gaps in Breast Cancer Chemotherapy
Initiation: The Role of the Patient-Provider Relationship. Breast Cancer Res Treat. 2013; 139: 207-216.

39. Fayanju OM, Jeffe DB, Elmore L, Ksiazek DN, Margenthaler JA. Patient and Process Factors Associated with LateStage Breast Cancer Diagnosis in Safety-Net Patients: A Pilot Prospective Study. Annals Surg Oncol. 2013; 20: 723732.

40. Ghazali SM, Othman Z, Cheong KC, Hock LK, Rozita W, et al. Non-Practice of Breast Self Examination and Marital Status are Associated with Delayed Presen-tation with Breast Cancer. Asian Pac J Cancer Prev. 2013; 14: 11411145.

41. Quaife SL, Forbes LJL, Ramirez AJ, Brain KE, Donnelly C, et al. Recognition of cancer warning signs and anticipated delay in help-seeking in a population sample of adults in the UK. British J Cancer. 2014; 110: 12-18.

42. Bodapati SL, Babu GR. Oncologist Perspectives on Breast Cancer Screening in India - Results from a Qualitative Study in Andhra Pradesh. Asian Pac J Cancer Prev. 2013; 14: 5817-5823.

43. Bourdeanu L, Luu T, Baker N, Swain- Cabriales S, Chung $\mathrm{CT}$, et al. Barriers to Treatment in Patients With Locally Advanced Breast Cancer. J Natl Compr Canc Netw. 2013; 11: 1193-1198.

44. Chintamani A, Tuteja R, Khandelwal M, Tandon R, Bamal S, et al. Patient and provider delays in breast cancer patients at-tending a tertiary care center: a prospective study. J R Soc Med. 2011; 2: 76.

45. Crowley MM, McCoy ME, Bak SM, Caron SE, Ko NY, et al. Challenges in the Delivery of Quality Breast Cancer Care: Initiation of Adjuvant Hormone Therapy at an Urban Safety Net Hospital. J Oncol Pharm Practise. 2014; 10: 107112.

46. Poum A, Promthet S, Duffy SW, Parkin MD. Factors Associated With Delayed Diagnosis of Breast Cancer in Northeast Thailand. J Epidemiol. 2014; 24: 102-108.

47. Vandergrift JL, Niland JC, Theriault RL, Edge SB, Wong YN, et al. Time to Adjuvant Chemotherapy for Breast Cancer in National Comprehensive Cancer Network Institutions. J Natl Cancer Inst. 2013; 105: 1912.

48. Price AJ, Ndom P, Atenguena E, Nouemssi JPM, Ryder RW. Cancer Care Challenges in Developing Countries. Cancer. 2012; 118: 3627-3635.

49. Beattie A. Detecting breast cancer in a general practice Like finding needles in a haystack? Austral Fam Physician. 2009; 38:1003-1006.

50. Innos K, Padrik P, Valvere V, Eelma E, Kütner R, et al. Identifying women at risk for delayed presentation of breast cancer: a cross-sectional study in Estonia. BMC Public Health. 2013; 13:947.

51. Lim JNW. Empirical Comparisons of Patient Delay and Help Seeking Models for Breast Cancer: Fitness of Models for Use and Generalisation. Asian Pac J Cancer Prev. 2011; 12: 1589-1595.

52. Maly RC, Leak B, Mojica CM, Liu Y, Diamant AL, Thind A. What Influences Diagnostic Delay in Low-In-come Wom- 
en with Breast Cancer. J Womens Health (Larchmt). 2011; 20: 1017-1023.

53. Partridge $A H$, Hughes ME, Ottesen RA, Wong YN, Edge SB, et al. The Effect of Age on Delay in Diagnosis and Stage of Breast Cancer. Oncologist. 2012; 17: 775-782.

54. Piñeros M, Sánchez RM, Perry F, García OA, Ocampo R, Cendales R. Demoras en el diagnóstico y tratamien $\neg$ to de mujeres con cáncer de mama en Bogotá, Colombia. Salud Pub Mex. 2011; 53: 478-485. 